\title{
NMR resonance assignments of NarE, a putative ADP-ribosylating toxin from Neisseria meningitidis
}

\author{
Ludovic Carlier · Christian Koehler • Daniele Veggi • \\ Mariagrazia Pizza $\cdot$ Marco Soriani $\cdot$ Rolf Boelens • \\ Alexandre M. J. J. Bonvin
}

Received: 24 June 2010/Accepted: 13 August 2010/Published online: 25 August 2010

(C) The Author(s) 2010. This article is published with open access at Springerlink.com

\begin{abstract}
NarE is a $16 \mathrm{kDa}$ protein identified from Neisseria meningitidis, one of the bacterial pathogens responsible for meningitis. NarE belongs to the ADP-ribosyltransferase family and catalyses the transfer of ADP-ribose moieties to arginine residues in target protein acceptors. Many pathogenic bacteria utilize ADP-ribosylating toxins to modify and alter essential functions of eukaryotic cells. NarE was proposed to bind iron through a $\mathrm{Fe}-\mathrm{S}$ center which is supposed to be implied in catalysis. We have produced and purified uniformly labeled ${ }^{15} \mathrm{~N}$ - and ${ }^{15} \mathrm{~N} /{ }^{13} \mathrm{C}-\mathrm{NarE}$ and assigned backbone and side-chain resonances using multidimensional heteronuclear NMR spectroscopy. These assignments provide the starting point for the three-dimensional structure determination of NarE and the characterization of the role of the $\mathrm{Fe}-\mathrm{S}$ center in the catalytic mechanism.
\end{abstract}

Keywords NarE $\cdot$ Pathogenic bacteria $\cdot$ ADP ribosylation $\cdot$ Meningitis $\cdot$ NMR

L. Carlier · C. Koehler · R. Boelens · A. M. J. J. Bonvin ( $ه)$

Bijvoet Center for Biomolecular Research, Science Faculty,

Utrecht University, Padualaan 8, 3584 CH Utrecht,

The Netherlands

e-mail: a.m.j.j.bonvin@uu.nl

D. Veggi $\cdot$ M. Pizza $\cdot$ M. Soriani

Novartis Vaccines and Diagnostics, 53100 Siena, Italy

Present Address:

L. Carlier

Laboratoire des Biomolécules, CNRS UMR7203, UPMC

Université Paris 06, 75005 Paris, France

\section{Biological context}

Neisseria meningitidis is a gram-negative bacterium best known for its role in meningitis and septicemia. This human-specific pathogen is considered as a major cause of morbidity and mortality during childhood in industrialized countries and is responsible for epidemics in Africa and in Asia (Genco and Wetzler 2010). Like most bacterial pathogens, $N$. meningitidis synthesizes a number of toxic products believed to target and kill their host cells. Among these toxins, proteins that exert ADP-ribosylation activity represent a large family of potentially lethal enzymes able to modify or disrupt essential functions of eukaryotic cells (Moss and Vaughan 1988). ADP-ribosyltransferases catalyze the transfer of a single ADP-ribosyl group from $\beta$-nicotinamide adenine dinucleotide $\left(\mathrm{NAD}^{+}\right)$onto specific amino acid residues of host cell proteins with the simultaneous release of nicotinamide (Althaus and Richter 1987). Many bacterial pathogens use ADP-ribosylating enzymes to block protein synthesis or to alter signal transduction by inactivating key target proteins such as GTP-binding proteins (Locht and Keith 1986).

The putative ADP-ribosylating NarE protein from $N$. meningitidis was recently identified on the basis of a profile-based computational approach (Masignani et al. 2003). NarE shares structural features with toxins from $V$. cholerae and E. coli, and, like cholera toxin and heat-labile enterotoxins, retains the capacity to ADP-ribosylate arginine and to hydrolyze NAD in ADP-ribose and nicotinamide. Another feature of NarE is its ability to bind iron through an iron-sulfur center (Fe-S) (Del Vecchio et al. 2009). Interestingly, site-directed mutagenesis and enzymatic assays showed that correct assembly of the ironbinding site is essential for transferase but not for hydrolase activity (Del Vecchio et al. 2009), suggesting for the first 
time an implication of a $\mathrm{Fe}-\mathrm{S}$ cluster in catalysis within the ADP-ribosyltransferase family. We here report the ${ }^{1} \mathrm{H},{ }^{15} \mathrm{~N}$ and ${ }^{13} \mathrm{C}$ assignments of NarE protein from $N$. meningitidis as a preliminary step towards characterizing its threedimensional structure and elucidating the role of the ironsulfur center in the catalytic mechanism.

\section{Methods and experiments}

The NarE gene was PCR amplified from the chromosomal DNA of N. meningitidis MC58 strain and cloned into a pET21b+ plasmid (Novagen) under the control of the T7 promoter. The resulting expression vector encodes a $17 \mathrm{kDa}$ fusion protein that contains the wild-type NarE sequence (145 residues) followed by a 8-residue C-terminal histidine-tag (LEHHHHHH) used for purification purposes. The pET21b+ plasmid was transformed into an Escherichia coli BL21 (DE3) expression strain. Recombinant protein was prepared from cells grown to an $\mathrm{OD}_{600}$ of $0.5-0.6$ at $37^{\circ} \mathrm{C}$ in a bacterial culture supplemented by $100 \mu \mathrm{g} / \mathrm{ml}$ ampicillin. Protein expression was then induced by addition of $1 \mathrm{mM}$ isopropyl-1-thio- $\beta$-D-galactopyranoside (IPTG), and the culture was further grown for $3 \mathrm{~h}$ at $37^{\circ} \mathrm{C}$. The cells were harvested by centrifugation $(8,000 \times g$ for $30 \mathrm{~min})$, resuspended in $50 \mathrm{mM}$ phosphate buffer ( $\mathrm{pH} 8.0$ ) containing $300 \mathrm{mM} \mathrm{NaCl}$, and lysed with a French press cell (SLM, Aminco). The soluble fraction enriched with the NarE protein was separated from the inclusion bodies by centrifugation at $39,200 \times \mathrm{g}$ for $45 \mathrm{~min}$, and loaded on a nickel affinity chromatography column (GE Healthcare). The protein was purified using IMAC standard protocols and an imidazole concentration of $125 \mathrm{mM}$ was required to elute recombinant NarE. A second step of purification was performed using anion exchange QHP chromatography (GE Healthcare). Fractions containing the target protein were collected at a $\mathrm{NaCl}$ concentration of $300 \mathrm{mM}$ and finally concentrated by ultrafiltration using a 3-kDa cutoff membrane (Millipore).
Fig. 1 Assigned ${ }^{15} \mathrm{~N}-{ }^{1} \mathrm{H}$ HSQC spectrum of the ${ }^{15} \mathrm{~N}$-labeled NarE protein acquired at $750 \mathrm{MHz}$ and $27^{\circ} \mathrm{C}$. Amide side-chain resonances are connected by solid lines
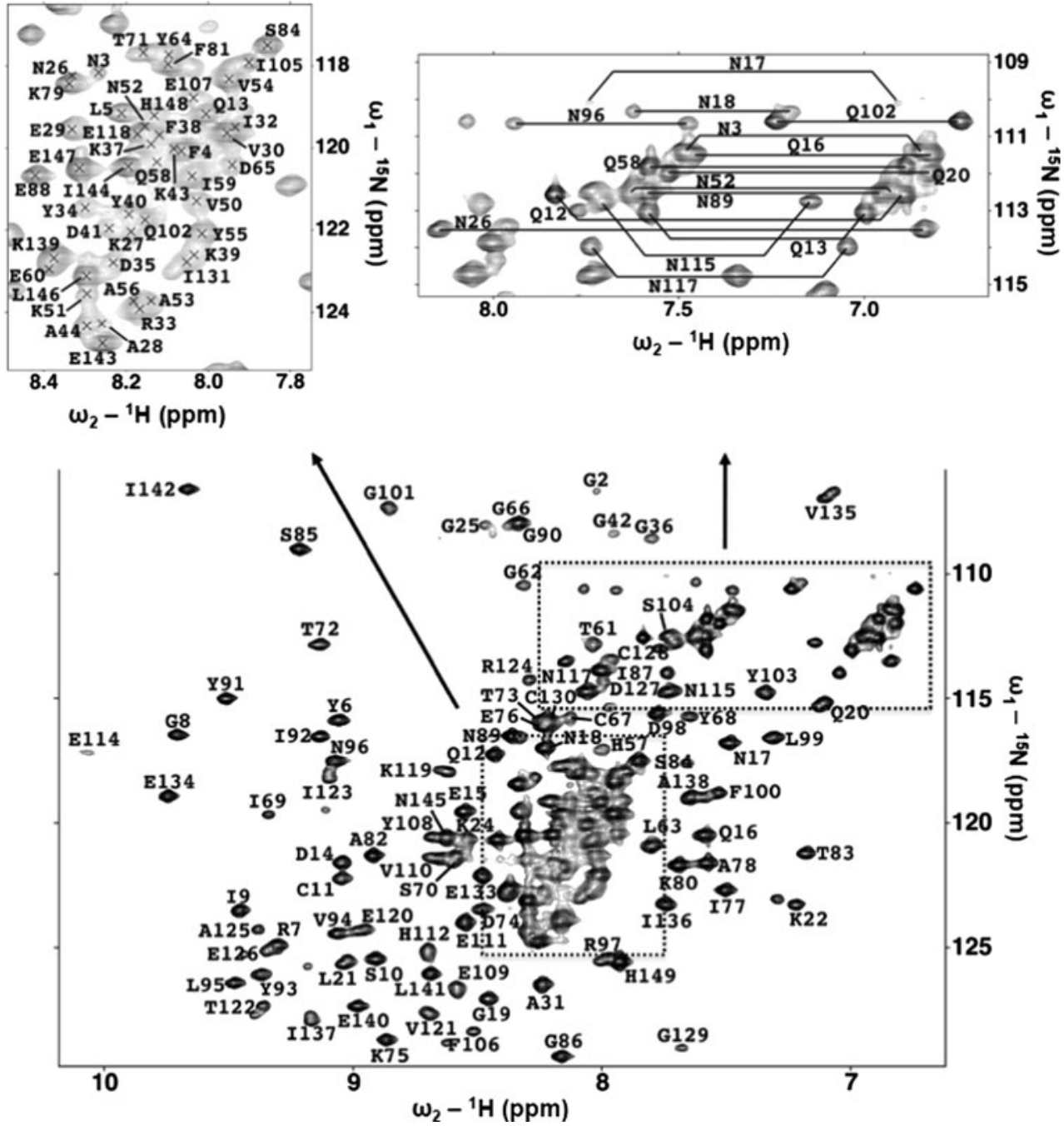
Expression of uniformly labeled ${ }^{15} \mathrm{~N}$ and ${ }^{15} \mathrm{~N} /{ }^{13} \mathrm{C}$ proteins was carried out by growing BL21 strains in ISOGRO- ${ }^{15} \mathrm{~N}$ and ISOGRO- ${ }^{15} \mathrm{~N},{ }^{13} \mathrm{C}$ rich media (Sigma), respectively. After buffer exchange and concentration, the resulting NMR samples contained approximately $0.6 \mathrm{mM}$ NarE protein in $25 \mathrm{mM}$ phosphate buffer $(\mathrm{pH} 7.5)$, $75 \mathrm{mM} \mathrm{NaCl}, 1 \mathrm{mM}$ PMSF, a protease inhibitor cocktail (Boehringer), $1 \mathrm{mM} \mathrm{NaN}_{3}$, and either $90 \% \mathrm{H}_{2} \mathrm{O} / 10 \% \mathrm{D}_{2} \mathrm{O}$ or $100 \% \mathrm{D}_{2} \mathrm{O}$. Trimethylsilyl-[2,2,3,3- $\left.{ }^{2} \mathrm{H}_{4}\right]$ propionate (TSP) was added as an internal ${ }^{1} \mathrm{H}$ chemical shift reference. ${ }^{13} \mathrm{C}$ and ${ }^{15} \mathrm{~N}$ chemical shifts were referenced indirectly to TSP, using the absolute frequency ratios (Wishart et al. 1995). NMR experiments were performed at $27^{\circ} \mathrm{C}$ on a Bruker Avance-II $750 \mathrm{MHz}$ equipped with a triple-resonance $\left({ }^{1} \mathrm{H},{ }^{15} \mathrm{~N},{ }^{13} \mathrm{C}\right)$ probe. Spectra recorded for sequential backbone assignment were as follows: $2 \mathrm{D}$ ${ }^{15} \mathrm{~N}-{ }^{1} \mathrm{H}$ HSQC, 3D HNCO, 3D HN(CA)CO, 3D HNCA, 3D $\mathrm{CBCA}(\mathrm{CO}) \mathrm{NH}, 3 \mathrm{D} \mathrm{CBCANH}$, and 3D HBHA (CO)NH. Aliphatic and aromatic ${ }^{1} \mathrm{H}$ and ${ }^{13} \mathrm{C}$ side chain assignments were obtained using 3D HCCH-TOCSY, 3D $\mathrm{HCCH}-\mathrm{COSY}$, and 3D $(\mathrm{H}) \mathrm{CC}(\mathrm{CO}) \mathrm{NH}$ experiments. All NMR data were processed with the NMRPipe software (Delaglio et al. 1995) and analysed with Sparky (Goddard and Kneller).

\section{Extent of assignments and data deposition}

Figure 1 shows the assigned ${ }^{1} \mathrm{H}-{ }^{15} \mathrm{~N}$ HSQC spectrum recorded on the ${ }^{15} \mathrm{~N}$-labeled protein sample. In this spectrum most of the cross-peaks are well-dispersed, indicating that recombinant NarE is well-folded in the NMR aqueous buffer. All the $\mathrm{NH}$ backbone resonances were assigned except for the N-terminal residue M1 and for S49 for which the absence of a cross-peak may be due to loop mobility or conformational exchange as this amino acid follows a proline in the NarE sequence. The lack of ${ }^{13} \mathrm{C}$ assignments for residue $\mathrm{P} 48$ due to line broadening confirms the presence of dynamics in this region of the protein. Interestingly, cysteines C67 and C128, which could be shown to be crucial for the coordination of iron (Del Vecchio et al. 2009), have a $C_{\beta}$ chemical shift value higher than $40 \mathrm{ppm}$, suggesting the formation of an intramolecular disulfide bridge between them in the absence of a reducing agent. Since the used protein samples were colourless and line broadening of NMR signals due to paramagnetic effects of iron-III could not be observed, the presented resonance assignment likely refers to the protein's apo-form.

Overall, all residues corresponding to NarE were identified: the backbone assignment is complete for ${ }^{1} \mathrm{H}_{\alpha}$ and reaches $98 \%$ for ${ }^{1} \mathrm{H}_{\mathrm{N}},{ }^{15} \mathrm{~N},{ }^{13} \mathrm{C}_{\alpha}$ and ${ }^{13} \mathrm{CO}$ nuclei. $88 \%$ of the aliphatic side chain resonances were assigned and $94 \%$

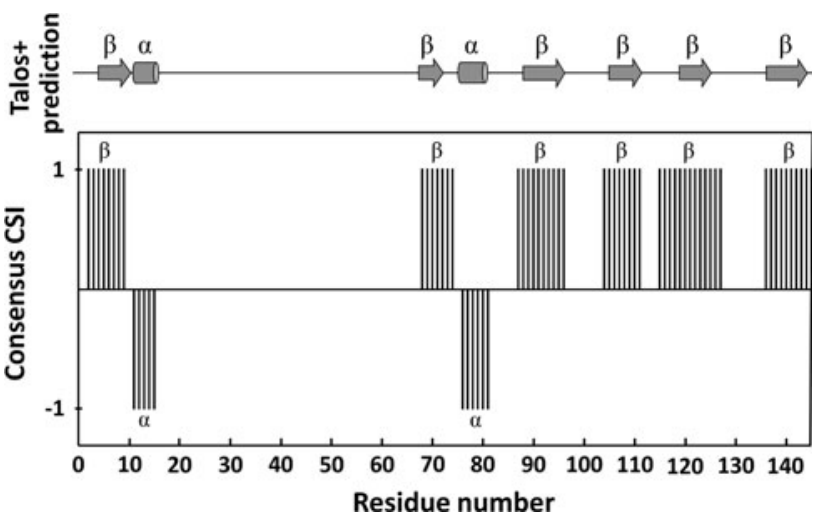

Fig. 2 Secondary structure prediction for the NarE sequence as obtained from TALOS + and consensus chemical shift index (CSI) programs. The regions identified to adopt $\alpha$-helical and $\beta$-strand secondary structures are named $\alpha$ and $\beta$, respectively

of the aromatic ${ }^{1} \mathrm{H}$ and ${ }^{13} \mathrm{C}$ resonances were identified including all Phe and Tyr residues. The assignment of $\mathrm{NH}_{2}$ side-chain resonances from asparagines and glutamines were also complete except for N145. The chemical shifts have been deposited into the BioMagResBank (http:// www.bmrb.wisc.edu) under accession number 16737. The CSI (Wishart and Sykes 1994) and TALOS+ (Shen et al. 2009) programs were used to evaluate NarE secondary structure from ${ }^{1} \mathrm{H}_{\alpha},{ }^{13} \mathrm{C}_{\alpha},{ }^{13} \mathrm{CO}$ and ${ }^{13} \mathrm{C}_{\beta}$ chemical shifts. As shown in Fig. 2, both methods are in agreement with the presence of two $\alpha$-helices (residues 11-15, and 76-81) and six $\beta$-strands (residues 4-9, 68-72, 88-96, 105-111, $118-125$ and 136-143).

Acknowledgments This work was supported by the Sixth Research Framework Programme of the European Community, FP6-STREP project "BacAbs", grant number LSHB-CT-2006-037325.

Open Access This article is distributed under the terms of the Creative Commons Attribution Noncommercial License which permits any noncommercial use, distribution, and reproduction in any medium, provided the original author(s) and source are credited.

\section{References}

Althaus FR, Richter C (1987) ADP-ribosylation of proteins. Enzymology and biological significance. Mol Biol Biochem Biophys 37:1-237

Del Vecchio M, Pogni R, Baratto MC, Nobbs A, Rappuoli R, Pizza M, Balducci E (2009) Identification of an iron-sulfur cluster that modulates the enzymatic activity in NarE, a Neisseria meningitides ADP-ribosyltransferase. J Biol Chem 284(48):3304033047

Delaglio F, Grzesiek S, Vuister GW, Zhu G, Pfeifer J, Bax A (1995) NMRPipe: a multidimensional spectral processing system based on UNIX pipes. J Biomol NMR 6:277-293

Genco C, Wetzler L (eds) (2010) Neisseria: molecular mechanisms of pathogenesis. Caister Academic Press, Norwich, UK 
Goddard TD, Kneller DG SPARKY 3. University of California, San Francisco. http://www.cgl.ucsf.edu/home/sparky/

Locht C, Keith JM (1986) Pertussis toxin gene: nucleotide sequence and genetic organization. Science 232:1258-1264

Masignani V, Balducci E, Di Marcello F, Savino S, Serruto D, Veggi D, Bambini S, Scarselli M, Arico B, Comanducci M, Adu-Bobie J, Giuliani M, Rappuoli R, Pizza M (2003) NarE: a novel ADPribosyltransferase from Neisseria meningitidis. Mol Microbiol 50(3): 1055-1067

Moss J, Vaughan M (1988) ADP-ribosylation of guanyl nucleotidebinding regulatory proteins by bacterial toxins. Adv Enzymol 61:303-379
Shen Y, Delaglio F, Cornilescu G, Bax A (2009) TALOS+: a hybrid method for predicting protein backbone torsion angles from NMR chemical shifts. J Biomol NMR 44:213-223

Wishart DS, Sykes BD (1994) The 13C chemical shift index. A simple method for the identification of protein secondary structure using $13 \mathrm{C}$ chemical shift data. J Biomol NMR 4:171-180

Wishart DS, Bigam CG, Yao J, Abildgaard F, Dyson HJ, Oldfield E, Markley JL, Sykes BD (1995) ${ }^{1} \mathrm{H},{ }^{13} \mathrm{C}$ and ${ }^{15} \mathrm{~N}$ chemical shift referencing in biomolecular NMR. J Biomol NMR 6:135-140 